Commentary paper for Research in Social and Administrative Pharmacy (RSAP) Journal

\title{
Implementing FIP's global pharmaceutical education transformation vision in Sub-Saharan African Countries
}

\author{
Authors: Nilhan Uzman ${ }^{1}$, Alison Ekwere Williams ${ }^{1,2}$, Ralph J. Altiere ${ }^{1}$, Claire Anderson ${ }^{1,3}$, Ian Bates ${ }^{1,4}$ \\ ${ }^{1}$ International Pharmaceutical Federation, The Hague, The Netherlands \\ ${ }^{2}$ International Pharmaceutical Students Federation, The Hague, The Netherlands \\ ${ }^{3}$ School of Pharmacy, The University of Nottingham, Nottingham, United Kingdom \\ ${ }^{4}$ School of Pharmacy, University College London, London, United Kingdom
}

Key words: Pharmacy, Pharmaceutical Sciences, Pharmacist, Education, Workforce, Africa, Transformation

\section{Corresponding Author information:}

Nilhan Uzman

International Pharmaceutical Federation

Andries Bickerweg 5, 2517JP, The Hague, Netherlands

education@fip.org

Declaration of Interest: No conflicts of interest

\begin{abstract}
The realization of a competent, versatile and adaptable Pharmaceutical workforce which is a key component in achieving the World Health Organization Universal Health Coverage agenda in 2030 depends on the supply of adequately trained pharmacy workforce who can improve access to quality medicines while delivering quality pharmaceutical services. Despite the rise in the density of pharmacists across all World Health Organization regions, African countries still stay considerably behind in terms of absolute capacity per capita which means that the pharmacy workforce in Africa continues to be very low and not adequate to deliver the pharmaceutical services needs of the region. The International Pharmaceutical Federation is leading the transformation of pharmacy education in Sub-Saharan African countries to bridge this gap with a spotlight on increasing academic capacity, establishing needs-based education strategies and creating an enabling practice environment through advocacy. This commentary paper seeks to discuss the strategies such as the FIP-UNITWIN Programme and the Kenya-Nottingham Partnership utilized in transforming the pharmacy education and therefore the pharmaceutical workforce within the Sub-Saharan African Countries. This paper also gives a clue on subsequent steps which can advance pharmaceutical practice and science in the region.
\end{abstract}

\section{About the FIP-UNITWIN Programme}

The health workforce variations, shortages and imbalances across regions and countries has been a global health challenge towards achieving universal health coverage. Access to essential medicines and 
appropriate use of medicines requires a competent, adaptable and adequate pharmaceutical workforce, as the medicines experts. Improvement of quality education and training has been identified as one of the key elements for the sustainable development of pharmaceutical workforce to improve health and well-being ${ }^{1}$.

UNITWIN, University Twinning and Networking, was first introduced in 1992 by UNESCO with the purpose of advancing research, training and developing of the academic programme through building university networks and encouraging inter-university cooperation through the transfer of knowledge across borders ${ }^{2}$.

In 2007, as part of the work programme for the newly established International Pharmaceutical Federation (FIP) Pharmacy Education Taskforce (PET), a proposal was developed to establish a network of schools of pharmacy from all regions of the world to participate in the FIP Action Plan process. This network was originally conceived to be a Global Deans network that would contribute towards consultations, share experiences and resources, provide data and assist with field testing of tools and frameworks.

To develop a network of schools of pharmacy an action plan that was drawn up for FIP by the PET and an application was made to UNESCO, in collaboration with University College London School of Pharmacy (UCL), to initiate the FIP-UNITWIN Global Pharmacy Education Development Network programme (FIPUNITWIN), in 2007. PET Action Plan came to fruition on March 2008 when it was officially launched with WHO and UNESCO at the Global Health Workforce Alliance Global Forum in Kampala, Uganda.

FIP, UNESCO and UCL considered that one of the essential factors favouring development in the fields of professional competence is the exchange of experience and knowledge between universities and other learning institutions together with collaborative practice between university teachers, researchers and administrators from different regions across the world.

\section{FIP-UNITWIN programme set out to provide:}

a) A mechanism across borders and boundaries, for sharing best educational practice between and amongst HEls and other education providers, including developing, piloting, and launching regionally-located Centres for Excellence for educational practice, which intended to be a significant leadership piece for FIP

b) A means for sharing resources across borders and boundaries, to the greater benefit of FIP members, either as individuals, organizations of higher education institutions, with a particular focus on LMICs

c) An advocacy mechanism for FIP members and the (at the time) newly launched AIM section (Global Dean's forum).

The FIP-UNITWIN programme is the first UNESCO programme with a non-governmental organization involvement through FIP, and the first programme for healthcare professions and education. The principal objectives of the FIP-UNITWIN Programme are to:

1. Promote an integrated system of research, training, information and documentation activities in the field of global pharmacy education; in particular, addressing issues of academic capacity, quality assurance of educational systems and workforce competency. 
2. Establish a dynamic and accessible database of faculties, educational data and resources for sharing within and outside the Network, facilitating North-South, South-South and intra-regional cooperation.

3. Establish a forum for discussion and debate on trends and developments in pharmacy education, facilitated by the Network partners, including NGOs and professional agencies.

4. Provide a mechanism for exchange of ideas, skills, resources and good practice, including staff exchange for skills and capacity building outcomes. These activities will also seek to promote gender equality and empowerment of women academics and scientists in collaborative research and policy development.

5. Foster international collaborative research, policy synthesis and strategic development with a particular focus on international development issues and sustainable practitioner development policies.

Under UNESCO conventions, bureaucratic and administrative functions for Networks are handled though the host Country Commission. Strategic decisions, operating goals, development streams and conduct are the functions of FIP and The FIP-UNITWIN network belongs to, and is operated by, FIP, aligned with FIP's vision, mission and strategic outcomes.

The FIP-UNITWIN and agreement allows use of a UNESCO designated logo, as seen below in Figure-2:

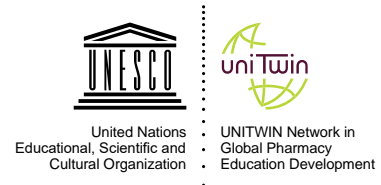

Figure 2 - UNESCO UNITWIN Logo

FIP-UNITWIN programme started its activities by setting up the FIP UNESCO-UNITWIN Center for Excellence in Africa (CFEA) with founding partners, deans or heads of pharmacy schools, from Ghana, Namibia, Nigeria, Uganda and Zambia. The activities of the FIP UNESCO-UNITWIN CfEA pertain to the field of pharmacy and pharmaceutical sciences. The domains concerned are global higher education, global higher education development with a special interest in Africa and other low-income countries, empowerment of women pharmaceutical scientists and academics, sustainable health workforce development, academic capacity building, quality assurance issues and accreditation standards.

Based on the specific needs of the founding partner countries, the FIP UNESCO-UNITWIN CFEA identified their areas of interest as:

1. Communications and Publications

2. Capability Training

3. Quality in Teaching and Learning

4. Innovations in IT and ICT delivery

5. Monitoring medicines use

6. Networking and resources 
Over the past 10 years since the FIP-UNITWIN and FIP UNESCO-UNITWIN CFEA were established, FIP has demonstrated strong implementation efforts and impact in the Sub-Saharan African countries in CfEA, aligned with FIP's global pharmacy education transformation agenda.

\section{FIP-UNESCO UNITWIN Center for Excellence in Africa}

Africa ranks as the second most populated continent in the world having about $17 \%$ of the total world's population with a poor, unstable and fragile health system. This translates to the continent being burdened with $25 \%$ of the world's disease but only $3 \%$ or less of the health care workers to meet health care needs $s^{3,4}$. The unavailability of sufficient, high quality and competent health workers including pharmacists puts public health at a major risk and it is evident that medicines and medicines access is an indispensable component of health care delivery critical for achieving universal health coverage ${ }^{5}$. About one-third of the Africa population do not have access to quality medicines and pharmaceutical services. There is a critical shortage of pharmacists who are the custodians and experts on medication in the continent ${ }^{5}$. Despite the increase in the density of pharmacists across all World Health Organization Regions, African countries still remain significantly behind in terms of absolute capacity per capita which implies that the pharmacy workforce in Africa is still very low and not sufficient to deliver the pharmaceutical services needs of the region ${ }^{6}$. The pharmacy is often the most accessible point for health care in developing countries and improvement in the availability, quality and competence of the pharmacy workforce is expected to make a significant improvement towards achieving universal health coverage.

Through the FIP-UNESCO UNITWIN Center for Excellence in Africa network, FIP has been engaging it's resources, expertise and networks towards transforming pharmacy education in Sub-Saharan African countries building on the premises that there is no workforce without education ${ }^{7}$.

The FIP UNESCO-UNITWIN CfEA partners contributed to an expertise and network mapping activity in order to purposefully match the needs and priorities with the existing experience in the group. This mapping and matching resulted in academic exchanges between the founding partners. The members established joint teaching programmes for their students, where the visiting academics had a chance to improve the academic capacity through these rapid knowledge exchanges.

In 2014, the CfEA has devised a project called LABBOX. The project aimed to develop a box of laboratory equipment suitable for a student, who will be able to conduct laboratory exercises in the curriculum and to improve pharmaceutical sciences competencies. University of Malawi Department of Pharmacy piloted the project with their $3^{\text {rd }}$ year pharmacy students and the first batch of students who have graduated, demonstrated improvement in educational outcomes, reported by the founding partner in University of Malawi Department of Pharmacy.

\section{Implementing FIP's global pharmaceutical education transformation vision in FIP-UNESCO UNITWIN CfEA}

In 2016, FIP brought together global health and pharmacy leaders from across the world to set the future milestones for pharmaceutical education in the context of workforce development during an exceptional event, which took place in Nanjing, China, on 7 and 8 November 2016: the Global Conference on Pharmacy and Pharmaceutical Sciences Education - "Creating a global vision for a global workforce". The conference set the future milestones for education and workforce development of pharmacists and pharmaceutical scientists ${ }^{7}$. 
Following extensive consultation, three milestone documents were presented and adopted at the global conference, which became the global pharmacy education transformation agenda of FIP:

1. A Global Vision for Education and Workforce that provides a description of the future directions of our profession and how education can support the evolution of science and practice.

2. A set of 13 Pharmaceutical Workforce Development Goals (PWDGs) which aim to facilitate the implementation of the global vision through a series of measurable, feasible and tangible goals.

3. A set of 67 statements on Pharmacy and Pharmaceutical Sciences Education ("the Nanjing Statements") that describe an envisioned future for education, to enable the enhancement of professional education standards worldwide.

In 2018, following the outcomes of the Nanjing Conference, FIP-UNESCO UNITWIN CfEA underwent a strategic retreat to align its objectives with FIP's global transformation agenda. The members of the FIPUNESCO UNITWIN CFEA responded to a series of questionnaires, based on using the Nanjing Statements, PWDGs and Global Competency Framework, to have a comprehensive understanding of the educational standards, academic curriculum, the scope of practice and pharmaceutical workforce needs ${ }^{8}$.

This activity was particularly significant because it was the first multi-country effort to successfully implement the outputs of the Nanjing conference to attain FIP's global vision for education and workforce. The results were discussed in a face to face meeting held in Nigeria in 2018 and the FIP-UNESCO UNITWIN CfEA objectives were identified as follows:

1. Increase academic capacity

2. Establish needs-based education strategies

3. Create an enabling environment through advocacy

\section{Increasing academic capacity}

Increasing the academic capacity will improve staff productivity ${ }^{9}$ and due to identified shortages in the number of academic staff and areas of specialization of staff; it is a necessity that to transform pharmacy education in these countries, the quality and quantity of academic staff must increase.

In 2019, the CfEA members developed and responded to an academic capacity survey, built on the 2013 FIPEd Global Education Survey ${ }^{10}$ and World Health Organization (WHO) National Health Workforce Accounts ${ }^{11}$ indicators focused on education. The results of the survey will be published in an overview report in 2020 by FIP to demonstrate the academic capacity needs and priorities among CfEA countries.

FIP organized a 2-day workshop and trainings for CfEA members in 2019, in Kenya, to improve academic knowledge and skills. The programme covered topics such as setting up new academic programmes, technology in Education, collaboration with overseas universities and experiential learning best practices.

\section{Establishing needs-based education strategies}

FIP's needs-based education ${ }^{10}$ model suggests that pharmaceutical education should be locally determined, socially accountable, globally connected, and quality assured to meet the given health needs of communities. The scope of practice survey that was conducted in 2018 for CfEA members, laid the foundation of an understanding of what are the health care needs and how pharmaceutical workforce provides tailored services to those needs. These initial results will be published in 2020 . 
Based on these results, CfEA members from University of Makerere, Uganda and University of Benin, Nigeria have been recruited to a pilot project jointly delivered by WHO and FIP. Uganda and Nigeria are amongst the countries who have been highly affected by substandard and falsified medicines, which is a major public health issue. The project aims to co-create and deliver a curriculum on substandard and falsified medical products to pharmacy students.

Building on PWDGs, FIP is currently developing a set of Global Development Goals, which will set the standards for pharmaceutical services, sciences and innovation, and workforce. The UNITWIN CfEA members will be a platform for FIP to deepen the understanding of health and services needs in CfEA countries to establish needs-based education strategies.

\section{Creating an enabling policy environment through advocacy}

Increasing academic capacity and implementing needs-based education strategies certainly requires appropriate legislation to be in place. The policies must be right to achieve transformation in pharmacy education.

FIP has been generating evidence and bringing attention to the needs of pharmacy education in Sub-Saharan Africa through FIP-UNESCO UNITWIN. FIP used its conveying power in 2019 to hold a regional panel on pharmacy education alongside Pharmaceutical Society of Kenya's annual symposium in Mombasa, Kenya. At the high-level panel discussion: "Achieving UHC by strengthening education and workforce: Regional needs and priorities", a multi-stakeholder group of panellists from academia, practice, professional advocacy and pharmacy students discussed linking up pharmacy practice to education, building essential competencies to meet the health care needs of the society and barriers/enablers in creating an policy environment to advance pharmacy education and practice.

Building on the outcomes of these discussions, FIP will hold a regional policy meeting in 2020 where key pharmacy and health care stakeholders will be convened to commit to action on transforming pharmacy education in Africa.

FIP-UNESCO UNITWIN CfEA members will also support the development of a pharmacy school association in Africa that advances the objectives of the FIP UNESCO UNITWIN programme. The challenges and needs are diverse across the region. However, consolidating the efforts and harmonizing pharmacy education in the region will demonstrate greater impact for pharmacy services and health care in Africa.

\section{FIP-Kenya-Nottingham Partnership}

Kenya intends to create a globally competitive and adaptive pharmacy workforce to meet the requirements of a rapidly industrialising economy. Regarding the rapid proliferation of pharmacy schools in the country, there is a need for adequate, well trained, motivated and productive academic workforce for effective teaching and learning ${ }^{12}$. The Kenya-Nottingham Partnership is part of the UK Aid-funded Strategic Partnerships for Higher Education Innovation and Reform (SPHEIR) programme. The partnership started in 2018, and partners on this project include the University of Nottingham, University of Nairobi, Kenyatta University, Jomo-Kenyatta University, Maseno University and Masai Mara University, FIP, Pharmaceutical Society of Kenya (PSK) and Kenyan Association of Manufacturers.

The project will enhance pedagogic, technical and entrepreneurial skills and mentor junior and women academics, who are still underrepresented especially at senior levels. The project aims to:

- create globally competitive and adaptive chemistry and pharmacy workforce to meet the requirements of a rapidly industrialising Kenyan economy.

- enhance collaboration between industry and academia on delivery of chemistry and pharmacy courses. 
- link learning outcomes and wider impacts at the individual, institutional, systemic and national levels.

- develop diagnostic models and benchmarking tools for developing academic capacity in pharmacy and chemistry.

FIP has embarked on this partnership project through its extensive experience in African context of pharmacy education built over the past years through FIP-UNESCO UNITWIN CFEA and its global pharmacy education and workforce transformation vision.

The main activities in the project are to:

- Evaluate existing curriculum.

- Input on local needs from employers, government, students and others using a national stakeholder meeting, surveys, interviews and facilitated meetings.

- Input Best Practice from UK and overseas through Nottingham and FIP UNITWIN,

- Co-develop new curricula - develop resources, case studies, lab skills, use of simulated patients and e learning.

- $\quad$ Provide training for curriculum deliverers (existing and new) and training the future trainers.

- Provide mentoring opportunities with colleagues at Nottingham and via UNITWIN African partners.

- Pilot and evaluate new curriculum in the partner universities.

- Plan for expansion and roll-out include production of toolkits for developing new curricular, engaging employers, on-line resources, report and publications.

The expected outputs of the project are:

- Development of new needs-based pharmacy and chemistry curricula in Kenya.

- Address shortages of specific skills in pharmacy and chemistry workforces.

- Development of public and private sector work placements, increasing skills and employability.

- Strengthened quality of local skills training.

- Development of sustainable ongoing training in teaching, learning and assessment skills for academic staff.

- Increased capability of academic staff, from training, mentoring etc.

- Maximise equity outcomes for women and people from underserved communities.

- Strengthening of pharmacy FIP UNITWIN programme in Africa and beyond.

As there are various synergies between FIP-UNESCO UNITWIN CfEA and Kenya-Nottingham Partnership, University of Nairobi School of Pharmacy and recently Kenyatta University School of Pharmacy have been recruited in the UNITWIN CFEA team since 2018.

FIP had led the initial mapping of the existing curriculum through FIP's Nanjing Statements, PWDGs and Global Competency Framework. FIP-UNESCO UNITWIN CfEA engagement has provided knowledge and experience exchange between Kenyan partners based on their needs. The CfEA partners have provided workshops and trainings on setting up new programmes, technology in education, experiential learning, training of postgraduate students, grants and research writing. 
FIP will be leading regional and global exchanges and mentorship between Kenyan partners, CfEA members and global network of pharmacy educators for rapid exchange of knowledge for academic capacity development. As the Kenya-Nottingham Partnership is a multi-stakeholder project, FIP will leverage this partnership to implement its Workforce Transformation Programme ${ }^{13}$ to strategically support Kenya in developing needs-based, national workforce development strategies, workforce planning and actions.

The longer term outcomes will include:

- Workforce development leading to Kenyan pharmacy and chemistry graduates gaining employment and economic opportunities in pharmacy and chemistry in healthcare and industries.

- Economic growth from development of higher education and the chemistry and pharmacy sectors.

- Impact on curriculum development in other African countries and beyond.

- Impact on academic capacity and career pathways for pharmacy and chemistry academics in Kenya and beyond

FIP will be communicating and disseminating the country level impact and outcomes to its wider regional and global network as the partnership model will demonstrate a proof of concept to establish a needs-based pharmacy education system with an ultimate goal of improving health outcomes and well-being.

\section{Conclusions and the way forward}

FIP will continue to implement its global vision on pharmacy education for FIP-UNESCO UNITWIN CfEA and Kenya-Nottingham Partnership for a flexible, adaptable and competent pharmaceutical workforce in the African region. 2020 marks the tenth-year anniversary of FIP-UNITWIN programme. On this milestone anniversary, FIP will consolidate its relationship with United Nations (through UNESCO), and build on the achievements of FIP-UNITWIN programme to broaden collaboration and network with new strategic stakeholders. FIP delivered two successful regional conferences for Eastern Mediterranean and European Regions in 2019. Through a regional event in 2020, FIP will focus on the scalability of the FIP-UNITWIN programme across Africa, to other regions and then to a global scale.

Based on the FIP Strategic Plan 2019-2024, FIP will lead pharmacists to become medication managers by embracing new roles in primary care or filling other gaps in the healthcare system, while developing new practice and interdisciplinary models to enhance patient access to pharmaceutical care ${ }^{14}$. To achieve its vision, FIP will establish sets of standards, the Global Development Goals, for practice and science development, as it was done for pharmaceutical workforce through PWDGs ${ }^{7}$. FIP will purposefully collect needs and priorities in pharmaceutical practice, science and education through its Global Pharmacy Observatory. Regionally and globally expanded FIP-UNITWIN programme will present a key platform to advance pharmaceutical practice and science, through the transformation of pharmaceutical education and workforce.

\section{References}

1. Anderson C, Bates I, Beck D, et al. The WHO UNESCO FIP Pharmacy Education Taskforce. Hum Resour Health. 2009;7(6). doi:10.1186/1478-4491-7-45

2. University Twinning and Networking | | UNESCO. http://www.unesco.org/en/university- 
twinning-and-networking/university-twinning-and-networking/. Accessed November 21, 2019.

3. Worldometers. Population of Africa (2016) - Worldometers. Worldometers.

https://www.worldometers.info/world-population/africa-population/. Published 2018. Accessed November 21, 2019.

4. WHO. WHO | The African Regional Health Report: The Health of the People. WHO.

https://www.who.int/bulletin/africanhealth/en/. Published 2017. Accessed November 21, 2019.

5. WHO. WHO: Efforts to expand access to medicines in Africa must be intensified.

https://www.who.int/medicines/news/2017/RP_2017_PR.pdf?ua=1. Published 2017. Accessed November 21, 2019.

6. Bates I, John C, Seegobin P, Bruno A. An analysis of the global pharmacy workforce capacity trends from 2006 to 2012. Hum Resour Health. 2018;16(1):1-9. doi:10.1186/s12960-018-0267-y

7. International Pharmaceutical Federation (FIP). Transforming Pharmacy and Pharmaceutical Sciences Education in the Context of Workforce Development. The Hague: International Pharmaceutical Federation; 2017.

8. Altiere R, Uzman N. Utilizing FIP Nanjing outcomes to transform pharmacy education and practice in FIP UNESCO UNITWIN Center for Excellence in Africa program.

https://www.monash.edu/_data/assets/pdf_file/0009/1821888/Altiere-Ralph-UTILIZING-FIPNANJING-OUTCOMES-TO-TRANSFORM-PHARMACY-EDUCATION-AND-PRACTICE-IN-FIP-UNESCOUNITWIN-CENTER-FOR-EXCELLENCE-IN-AFRICA-PROGRAM.pdf. Published 2019. Accessed December 2, 2019.

9. Ozurumba CN, Amasuomo JO. Academic Staff Development and Output in State Universities in South-South Nigeria. Makerere J High Educ. 2015;7(2):49-59.

10. International Pharmaceutical Federation (FIP). 2013 FIPEd Global Education Report. The Hague: International Pharmaceutical Federation; 2017.

11. National health workforce accounts: a handbook. Geneva: World Health Organization; 2017. Licence: CC BY-NC-SA 3.0 IGO

12. Ikoni JO, Titus MK, Onesmus WG, Julius WM. Development of Pharmacy Education in Kenya Universities to date. African J Pharm Pharmacol. 2016;10(18):385-392.

doi:10.5897/ajpp2015.4407

13. International Pharmaceutical Federation (FIP). The FIP Workforce Transformation Programme (WTP) Fédération Internationale Pharmaceutique International Pharmaceutical Federation.; 2019. https://www.fip.org/files/fip/PharmacyEducation/2019/FIP-WTP-program-web.pdf. Accessed December 2, 2019.

14. International Pharmaceutical Federation (FIP). Strategic Plan 2019 to 2024.; 2019. https://www.fip.org/files/content/about/vision-mission/FIP-strategic-plan-2019-2024.pdf. Accessed December 2, 2019. 
